\title{
Synthesis and Property of Silicone Polymer from Chrysotile Asbestos by Acid-Leaching and Silylation
}

\author{
Shigeki Habaue, ${ }^{1,4}$ Tetsuya Hirasa, ${ }^{1}$ Yuichi Akagi, ${ }^{1}$ Kiyotsugu Yamashita, ${ }^{2}$ \\ and Meisetsu Kajiwara ${ }^{3}$
}

ERRATUM TO: JOURNAL OF INORGANIC AND ORGANOMETALLIC POLYMERS AND MATERIALS, VOL. 16, NO. 2 DOI 10.1007/ s10904-006-9038-7

The submitted and accepted dates for this paper were inadvertently omitted. The dates are as follows: Submitted January 9, 2006; accepted February 20, 2006

The online version of the original article can be found at http:// dx.doi.org/10.1007/s10904-006-9038-7

${ }^{1}$ Faculty of Engineering, Department of Chemistry and Chemical Engineering, Yamagata University, Yonezawa, Yamagata, 9928510, Japan.

${ }^{2}$ Nozawa Corporation, Orinokuchi, Fukaya, Saitama, 366-0812, Japan.

3 School of Dentistry, Aichi-Gakuin University, Chikusa-ku, Nagoya, 464-0034, Japan.

${ }^{4}$ To whom correspondence should be addressed.

E-mail: habaue@yz.yamagata-u.ac.jp 